\title{
Screening for perceived stress among pregnant women availing antenatal care at a tertiary care teaching institution in Kerala, India
}

\author{
Heera Shenoy T.*, Remash K., Sheela Shenoy T.
}

\begin{abstract}
${ }^{1}$ Department of Obstetrics and Gynecology, KMCT Medical College and Hospital, Kozhikode, Kerala, India ${ }^{2}$ Department of Medicine, Malabar Medical College Hospital and Research Centre, Kozhikode, Kerala, India ${ }^{3}$ Department of Obstetrics and Gynecology, Government Medical College, Thiruvananthapuram, Kerala, India
\end{abstract}

Received: 24 May 2020

Accepted: 03 July 2020

\author{
*Correspondence: \\ Dr. Heera Shenoy T., \\ E-mail: heerarprabhu@gmail.com
}

Copyright: () the author(s), publisher and licensee Medip Academy. This is an open-access article distributed under the terms of the Creative Commons Attribution Non-Commercial License, which permits unrestricted non-commercial use, distribution, and reproduction in any medium, provided the original work is properly cited.

\begin{abstract}
Background: Stress during pregnancy can have serious adverse outcomes on the mother, the foetus and the newborn. It can lead to low-birth-weight, preterm births and neuro-psychological effects such as anxiety and depression during pregnancy and puerperium. This cross-sectional research aims to assess the severity of stress among postnatal women in Kerala. This study analysed socio-demographic, obstetric, family dynamics, neonatal characteristics and psychiatric determinants of postpartum stress using perceived stress scale (PSS) among postnatal women in a tertiary hospital in Kerala state, India.

Methods: 119 women between 2 to 6 weeks of postpartum period were subjected to a pre-tested pre-structured standard questionnaire. Terminal illness, still birth delivery and comorbid psychiatric illness was excluded. Screening and diagnosis of postpartum stress was done based on perceived stress scale (PSS) and graded as mild 0-13, moderate 14-26, severe 27-40.

Results: Study findings indicated a statistically significant association between postpartum stress and risk factors such as unplanned/unwanted pregnancy. The mean age of women was $27 \pm 4.8$ years. Support from spouse and in-laws was a negative predictor of developing both postnatal stress and depression. Family income, education of couple and husbands' occupations were non-determinant factors $(\mathrm{p}>0.05)$ in this study. Psychiatric illness in the family and past history of psychiatric illness also contributed to postnatal stress. The most important variable which influenced perceived stress during pregnancy was lengthier NICU stay. Even breastfeeding problems and associated neonatal issues worsened the stress scales significantly in the immediate postnatal period.

Conclusions: This research concluded that stress detection and timely counselling along with mental and physical support will mitigate stress and postpartum depression.
\end{abstract}

Keywords: Determinants, Perceived stress scale, Post-partum depression, Postnatal stress, Risk factors, Social factors, Screening

\section{INTRODUCTION}

Pregnancy is recognized as a stressful event in a woman's life that needs huge psychological adjustment, however, it is often an exciting time. ${ }^{1,2}$ Pregnancy stress is defined as "the imbalance that a pregnant woman feels when she cannot cope with demands, which is expressed both behaviourally and physiologically". ${ }^{3}$ Also, Littlet one et al have determined "pregnancy-specific anxiety" as concerns, worries about pregnancy, fear of childbirth, infant well-being and future parenting. ${ }^{4}$

Perceived stress is the feelings or thoughts that an individual has about how much stress they are under at a 
given time or over a given period, how an individual feels about the general stressfulness of their life and their ability to handle such stress. ${ }^{5}$

The 'foetal programming hypothesis' was confirmed, stating that prenatal events and stressors are programming the infant brain and its metabolism via the stress hormone cortisol. ${ }^{6,7}$ It is well documented that stress during pregnancy can have a huge number of maternal as well as neonatal adverse effects. Many researchers have asserted that maternal stress during pregnancy has been associated with spontaneous pregnancy loss, preterm labour, low birth weight, preeclampsia, pregnancy loss, immune system suppression, excessive nausea and vomiting of pregnancy and higher incidence of caesarean deliveries. ${ }^{8-11}$ In addition, children of stressed and depressed mothers are at risk for delays in growth and development and reduced cognitive, neuropsychological, social and emotional skills across childhood and into adolescence. ${ }^{12}$ Given the profound disruptive influences of postnatal stress and depression for both mother and child, the detection and early treatment of vulnerable women at risk for the same is essential.

Additionally, maternal stress has been defined as a potential predictor of depression during and after pregnancy and schizophrenia among male offspring. ${ }^{13-17}$ Public health system can have spill-over effects from both short- and long-term effects of stress. Many factors have been identified as effectual elements increasing or decreasing the stress level. These include social support, quality of life and socioeconomic status. ${ }^{18-20}$ Among these three mentioned factors, socioeconomic status plays a crucial role in the stress perceived by pregnant women. ${ }^{21,22}$ This means that pregnant women with low socioeconomic status can experience greater stress during pregnancy rather than those with higher socioeconomic status. $^{23}$ Socioeconomic concerns, household chores, adverse life events, chronic illness of relatives and pregnancy-related concerns were also identified as important stressors. Child care stress, breastfeeding issues, partner abuse/violence, gender issues (fear and preference towards any particular gender) create unnecessary stress in women in some parts of our country. The psychological changes during pregnancy depend upon whether the pregnancy was planned or unplanned, wanted or unwanted, achieved in good time or after a long and anxious wait or after medical intervention like in vitro fertilization, fear of changes in the relationships such as divorce, and availability of socio-cultural support in raising the child. ${ }^{24}$

Stress is a precursor to anxiety and depression during pregnancy. Women with stress have a higher prevalence of anxiety and depression during pregnancy and the puerperal period. ${ }^{25,26}$ ACOG advocated screening all women for psychosocial stress and other psychosocial issues during each trimester of pregnancy and the postpartum period. ${ }^{27}$ Our health care policy has to emphasise the need for greater awareness among the public and healthcare professionals regarding postpartum stress by creating informative sessions and local resources to be made available for the optimal treatment of women suffering from it. At risk mothers have to be contacted and re-assured.

The Perceived Stress Scale (PSS) is the most widely used psychological instrument for measuring the perception of stress. Scale items have identified potential areas of counselling for pregnant women to prevent stress and depression. Regarding the importance of the relationship between determinants of maternal stress and its adverse outcomes, there are still gaps in the existing literature.

Kerala is a state with $100 \%$ literacy and nearly $100 \%$ institutional delivery and access to health care. Still the maternal mortality rate and morbidity, neonatal mortality rate and morbidity contributed by preterm labour and low birth rate are on higher side. Therefore, we conducted the present research to explore the determinants and severity of stress during pregnancy.

\section{METHODS}

A cross-sectional study was performed among women delivered in Travancore Medical College and hospital. This study was conducted in department of Obstetrics and gynecology of a tertiary care hospital in the state of Kerala, India from December 2018 to March 2019. The institution attached to a medical college is recognized by Medical Council of India with teaching facility for both under and postgraduates in obstetrics and gynecology.

A total of 119 women, who were in their postpartum state (2-6 weeks) were subjected to a pre-tested, pre-structured, standardized questionnaire, after obtaining an informed written consent. Women with acute severe illness or cognitive impairment or not willing to consent for voluntary participation were excluded. Primary outcome variable was the prevalence of postnatal stress and secondary outcome variable was various risk factors/determinants for Postnatal stress. Data was collected using predesigned and pretested questionnaire.

Screening and diagnosis of postpartum stress was done based on perceived stress scale (PSS) and graded as mild 0-13, moderate 14-26, severe 27-40.

The perceived stress scale (PSS) is the most widely used psychological instrument for measuring the perception of stress. It is a measure of the degree to which situations in one's life are appraised as stressful. Items were designed to tap how unpredictable, uncontrollable, and overloaded respondents find their lives. The scale also includes a number of direct queries about current levels of experienced stress. In each case, respondents are asked how often they felt a certain way. Maternal stress was assessed by the 10-item perceived stress scale, PSS by Sheldon Cohen (Cohen et al), which determines the 
degree to which situations during the last month had been appraised as stressful. The items are easy to understand and the response alternatives are simple to grasp. It is rated on a five-point scale ranging from 'never' to 'very often'. Malayalam version of the stress scale questionnaire was used to calculate the prevalence of postnatal stress in the present study. PSS scores are obtained by reversing responses (e.g., $0=4,1=3,2=2,3=1$ and $4=0$ ) to the four positively stated items (items $4,5,7$, and 8) and then summing across all scale items. The questionnaire takes approximately 5 minutes to complete. Informed written consent was taken from every participant. To ensure participant privacy data was collected in a separate room.

Ethical approval was obtained from the institutional ethical committee. Each woman was informed about the objectives of study and implications in providing their personal information and only consented women were recruited in the study. They had freedom to opt out from the study without affecting their rights of getting consultation at the hospital. Patient's information was dealt with confidentiality. Ethical clearance was obtained from Institutional Ethics Committee. Data analysis was done by using SPSS 21 trial version.

\section{Assessment of risk factors}

A questionnaire was designed and pretested for the assessment of risk factors for Postnatal stress based on previously reported risk factors.

\section{The questionnaire included}

Social and demographic details including age, educational qualification, family structure (nuclear/joint), occupation, environmental health status (housing, overcrowding), and socio-economic status.
The anthropometry (pre-pregnancy weight, height, body mass index-BMI) were noted.

Obstetric history including number and gender of children, present pregnancy (wanted/unwanted, planned/ unplanned, fears and expectations. regarding gender of child, mode of delivery, complications both during pregnancy and delivery). Data obtained by interview were checked against medical records and antenatal care cards, especially for obstetric history.

Infant characteristics like birth weight, NICU stay, breast -feeding issues and child-care stress.

History of previous personal and $1^{\text {st }}$ degree family psychiatric disorder, and treatment for the same.

Support from the family including relationship with the spouse, parents, and in-laws.

Addictions in spouse (smoking and alcohol) was enquired and domestic abuse/violence were asked.

\section{RESULTS}

In total, 119 new post-natal cases participated in the study. Screening and diagnosis of postpartum stress was done based on perceived stress scale (PSS) and graded as mild 0-13, moderate 14-26, severe 27-40.

The mean age of the sample was 27.13 years. Out of total 119 women, $92(77.31 \%)$ were diagnosed with stress using PSS score $>14$ in the study. On comparing the socio-demographic factors among women with depression and women without depression, age, education, employment of parents or income had no any association with the postnatal stress.

Table 1: Socio-demographic factors and stress in postnatal women.

\begin{tabular}{|c|c|c|c|c|c|}
\hline \multirow{2}{*}{$\begin{array}{l}\text { Variable } \\
\text { mother's age }\end{array}$} & \multicolumn{3}{|c|}{ Perceived stress scale (PSS) } & \multirow[b]{2}{*}{ Chi-square } & \multirow[b]{2}{*}{ p-value } \\
\hline & 0-13 Mild & 14-26 MOD & 27-40 SEV & & \\
\hline$<20$ & $1(3.7 \%)$ & $4(4.5 \%)$ & $0(0.0 \%)$ & \multirow{3}{*}{3.061} & \multirow{3}{*}{0.548} \\
\hline $20-30$ & $24(88.9 \%)$ & $67(75.3 \%)$ & $2(66.7 \%)$ & & \\
\hline$>30$ & $2(7.4 \%)$ & $18(20.2 \%)$ & $1(33.3 \%)$ & & \\
\hline \multicolumn{6}{|l|}{ Father age } \\
\hline$<35$ & $19(70.4 \%)$ & $62(69.7 \%)$ & $2(66.7 \%)$ & \multirow{2}{*}{0.019} & \multirow{2}{*}{0.991} \\
\hline$>35$ & $8(29.6 \%)$ & $27(30.3 \%)$ & $1(33.3 \%)$ & & \\
\hline \multicolumn{6}{|l|}{ Domicile } \\
\hline Urban & $15(55.6 \%)$ & $53(59.6 \%)$ & $2(66.7 \%)$ & \multirow{2}{*}{0.215} & \multirow{2}{*}{0.898} \\
\hline Rural & $12(44.4 \%)$ & $36(40.4 \%)$ & $1(33.3 \%)$ & & \\
\hline \multicolumn{6}{|l|}{ Status mother } \\
\hline Booked & $18(66.7 \%)$ & $62(69.7 \%)$ & $3(100 \%)$ & \multirow{3}{*}{1.423} & \multirow{3}{*}{0.491} \\
\hline Referred & $9(33.3 \%)$ & $27(30.3 \%)$ & $0(0.0 \%)$ & & \\
\hline \multicolumn{4}{|c|}{ Education mother } & & \\
\hline Tenth & $4(14.8 \%)$ & $6(6.7 \%)$ & $0(0.0 \%)$ & 5.165 & 0.523 \\
\hline
\end{tabular}




\begin{tabular}{|c|c|c|c|c|c|}
\hline \multirow{2}{*}{$\begin{array}{l}\text { Variable } \\
\text { mother's age }\end{array}$} & \multicolumn{3}{|c|}{ Perceived stress scale (PSS) } & \multirow{2}{*}{ Chi-square } & \multirow[b]{2}{*}{ p-value } \\
\hline & 0-13 Mild & 14-26 MOD & 27-40 SEV & & \\
\hline Plus, two & $4(14.8 \%)$ & $23(25.8 \%)$ & $0(0.0 \%)$ & & \\
\hline Graduate & $11(40.7 \%)$ & $29(32.6 \%)$ & $1(33.3 \%)$ & & \\
\hline Post graduate & $8(29.6 \%)$ & $31(34.8 \%)$ & $2(66.7 \%)$ & & \\
\hline \multicolumn{6}{|l|}{ Education father } \\
\hline Primary & $1(3.7 \%)$ & $3(3.4 \%)$ & $1(33.3 \%)$ & \multirow{5}{*}{12.577} & \multirow{5}{*}{0.127} \\
\hline Tenth & $8(29.6 \%)$ & $18(20.2 \%)$ & $0(0.0 \%)$ & & \\
\hline Plus, two & $3(11.1 \%)$ & $15(16.9 \%)$ & $0(0.0 \%)$ & & \\
\hline Graduate & $5(18.5 \%)$ & $33(37.1 \%)$ & $1(33.3 \%)$ & & \\
\hline Post graduate & $10(37.0 \%)$ & $20(22.5 \%)$ & $1(33.3 \%)$ & & \\
\hline \multicolumn{6}{|c|}{ Employment mother } \\
\hline Employed & $10(37.0 \%)$ & $30(33.7 \%)$ & $1(33.3 \%)$ & \multirow{2}{*}{0.103} & \multirow{2}{*}{0.950} \\
\hline Unemployed & $17(63.0 \%)$ & $59(66.3 \%)$ & $2(66.7 \%)$ & & \\
\hline \multicolumn{6}{|c|}{ Employment father } \\
\hline Employed & $24(88.9 \%)$ & $84(94.4 \%)$ & $2(66.7 \%)$ & \multirow{2}{*}{3.818} & \multirow{2}{*}{0.148} \\
\hline Unemployed & $3(11.1 \%)$ & $5(5.6 \%)$ & $1(33.3 \%)$ & & \\
\hline \multicolumn{6}{|l|}{ Housing } \\
\hline Own & $23(85.2 \%)$ & $80(89.9 \%)$ & $3(100 \%)$ & \multirow{2}{*}{0.848} & \multirow{2}{*}{0.654} \\
\hline Rented & $4(14.8 \%)$ & $9(10.1 \%)$ & $0(0.0 \%)$ & & \\
\hline \multicolumn{6}{|l|}{ Family } \\
\hline Joint & $22(81.5 \%)$ & $71(79.8 \%)$ & $2(66.7 \%)$ & \multirow{2}{*}{0.369} & \multirow{2}{*}{0.832} \\
\hline Nuclear & $5(18.5 \%)$ & $18(20.2 \%)$ & $1(33.3 \%)$ & & \\
\hline \multicolumn{6}{|l|}{ Income } \\
\hline Low and middle & $8(29.6 \%)$ & $22(24.7 \%)$ & $0(0.0 \%)$ & \multirow{3}{*}{3.220} & \multirow{3}{*}{0.522} \\
\hline Middle & $11(40.7 \%)$ & $44(49.4 \%)$ & $1(33.3 \%)$ & & \\
\hline High & $8(29.6 \%)$ & $23(25.8 \%)$ & $2(66.7 \%)$ & & \\
\hline
\end{tabular}

Table 2: Marital factors and postnatal stress.

\begin{tabular}{|c|c|c|c|c|c|}
\hline Age at marriage in years & $\begin{array}{l}\text { PSS (0-13) } \\
\text { Mild stress }\end{array}$ & $\begin{array}{l}\text { PSS }(14-26) \\
\text { Moderate stress }\end{array}$ & $\begin{array}{l}\text { PSS (27-40) } \\
\text { Severe stress }\end{array}$ & Chi -square & p-value \\
\hline$<20$ & $7(25.9 \%)$ & $30(33.7 \%)$ & $0(0.0 \%)$ & \multirow{3}{*}{3.284} & \multirow{3}{*}{0.512} \\
\hline $20-30$ & $20(74.1 \%)$ & $56(62.9 \%)$ & $3(100 \%)$ & & \\
\hline$>30$ & $0(0.0 \%)$ & $3(3.4 \%)$ & $0(0.0 \%)$ & & \\
\hline \multicolumn{6}{|l|}{ Type of marriage } \\
\hline Arranged & $24(88.9 \%)$ & $66(74.2 \%)$ & $2(66.7 \%)$ & \multirow{3}{*}{3.228} & \multirow{3}{*}{0.520} \\
\hline Love & $3(11.1 \%)$ & $20(22.5 \%)$ & $1(33.3 \%)$ & & \\
\hline Arranged cum love & $0(0.0 \%)$ & $3(3.4 \%)$ & $0(0.0 \%)$ & & \\
\hline \multicolumn{6}{|l|}{ Gravida } \\
\hline Primigravida & $12(44.4 \%)$ & $43(49.4 \%)$ & $2(66.7 \%)$ & \multirow{2}{*}{0.602} & \multirow{2}{*}{0.740} \\
\hline G2 and above & $15(55.6 \%)$ & $44(50.6 \%)$ & $1(33.3 \%)$ & & \\
\hline
\end{tabular}

Table 3: Planned pregnancy and postnatal stress.

\begin{tabular}{|llllll|}
\hline Wanted pregnancy & PSS -Mild & PSS-Moderate & PSS-Severe & Chi square & p-value \\
\hline Yes & $24(88.9 \%)$ & $86(96.6 \%)$ & $2(66.7 \%)$ & \multirow{2}{*}{6.431} & \multirow{2}{*}{$0.040^{*}$} \\
\hline No & $3(11.1 \%)$ & $3(3.4 \%)$ & $1(33.3 \%)$ & & \\
\hline Planned pregnancy & & & & & \multirow{2}{*}{$0.001 *$} \\
\hline Yes & $16(59.3 \%)$ & $84(94.4 \%)$ & $1(33.3 \%)$ & \multirow{2}{*}{26.274} & \multirow{2}{*}{ No } \\
\hline
\end{tabular}

Comparison of the obstetric factors among women with varying degrees of postnatal stress, it showed that stress was not significantly associated with age at marriage, type of marriage, gravida and interpregnancy interval. 
Unplanned pregnancy was a predictor of stress in pregnant women (p value-0.001). Mean gestational age and birthweight was comparable in both the groups. Gender fear and preference for a particular gender was not a predictor of postnatal stress in this research.
The most important variable which influenced perceived stress during pregnancy was lengthier NICU stay. Even breastfeeding problems and associated neonatal issues worsened the stress scales significantly in the immediate postnatal period.

Table 4: Gestational age, birthweight and gender issues and postnatal stress.

\begin{tabular}{|c|c|c|c|c|c|}
\hline \multirow{2}{*}{ Gestational age in weeks } & \multicolumn{3}{|c|}{ PSS (perceived stress scale) } & \multirow[b]{2}{*}{ Chi square } & \multirow{2}{*}{ p-value } \\
\hline & 0-13 PSS Mild & 14-26 MOD & 27-40 SEV & & \\
\hline$<28$ & $1(3.7 \%)$ & $4(4.5 \%)$ & $0(0.0 \%)$ & \multirow{4}{*}{6.568} & \multirow{4}{*}{0.363} \\
\hline $28-33.6$ & $2(7.4 \%)$ & $10(11.2 \%)$ & $0(0.0 \%)$ & & \\
\hline $34-36.6$ & $0(0.0 \%)$ & $12(13.5 \%)$ & $1(33.3 \%)$ & & \\
\hline$>37$ & $24(88.9 \%)$ & $63(70.8 \%)$ & $2(66.7 \%)$ & & \\
\hline \multicolumn{6}{|l|}{ Baby weight in grams } \\
\hline$<1499$ & $3(11.1 \%)$ & $8(9.0 \%)$ & $0(0.0 \%)$ & \multirow{4}{*}{3.36} & \multirow{4}{*}{0.762} \\
\hline $1500-2499$ & $4(14.8 \%)$ & $22(24.7 \%)$ & $1(33.3 \%)$ & & \\
\hline 2500-3499 & $16(59.3 \%)$ & $50(56.2 \%)$ & $1(33.3 \%)$ & & \\
\hline$>3500$ & $4(14.8 \%)$ & $9(10.1 \%)$ & $1(33.3 \%)$ & & \\
\hline \multicolumn{6}{|l|}{ Baby gender } \\
\hline Female & $15(55.6 \%)$ & $51(57.3 \%)$ & $2(66.7 \%)$ & \multirow{2}{*}{0.14} & \multirow{2}{*}{0.932} \\
\hline Male & $12(44.4 \%)$ & $38(42.7 \%)$ & $1(33.3 \%)$ & & \\
\hline \multicolumn{6}{|l|}{ Gender fear } \\
\hline Yes (fear of particular gender) & $7(25.9 \%)$ & $31(34.8 \%)$ & $3(100 \%)$ & \multirow{2}{*}{7.21} & \multirow{2}{*}{0.125} \\
\hline No & $20(74.1 \%)$ & $58(65.2 \%)$ & $0(0.0 \%)$ & & \\
\hline \multicolumn{6}{|l|}{ Preferred gender } \\
\hline Female & $10(37.0 \%)$ & $23(25.8 \%)$ & $1(33.3 \%)$ & \multirow{3}{*}{3.243} & \multirow{3}{*}{0.518} \\
\hline Male & $8(29.6 \%)$ & $37(41.6 \%)$ & $2(66.7 \%)$ & & \\
\hline No such preference & $9(33.3 \%)$ & $29(32.6 \%)$ & $0(0.0 \%)$ & & \\
\hline
\end{tabular}

Table 5: Neonatal details and stress in postnatal women.

\begin{tabular}{|c|c|c|c|c|c|}
\hline \multicolumn{6}{|c|}{ PSS (perceived stress scale ) } \\
\hline NICU admission & PSS-Mild & PSS-MOD & PSS-Severe & Chi square & p-value \\
\hline Yes & $12(44.4 \%)$ & $35(39.3 \%)$ & $2(66.7 \%)$ & 1.050 & \multirow{2}{*}{0.592} \\
\hline No & $15(55.6 \%)$ & $54(60.7 \%)$ & $1(33.3 \%)$ & & \\
\hline \multicolumn{6}{|l|}{ Days in NICU } \\
\hline$<2$ days & $22(81.5 \%)$ & $66(74.2 \%)$ & $1(33.3 \%)$ & 12.417 & \multirow{3}{*}{$0.015^{*}$} \\
\hline 3-7 days & $4(14.8 \%)$ & $8(9.0 \%)$ & $2(66.7 \%)$ & & \\
\hline$>7$ days & $1(3.7 \%)$ & $15(16.9 \%)$ & $0(0.0 \%)$ & & \\
\hline \multicolumn{6}{|l|}{ Child care stress } \\
\hline Yes & $3(11.1 \%)$ & $17(19.1 \%)$ & $1(33.3 \%)$ & 1.431 & \multirow{2}{*}{0.489} \\
\hline No & $24(88.9 \%)$ & $72(80.9 \%)$ & $2(66.7 \%)$ & & \\
\hline \multicolumn{6}{|c|}{ Breast feeding issues } \\
\hline Yes & $14(51.9 \%)$ & $24(27.0 \%)$ & $2(66.7 \%)$ & 7.256 & \multirow{2}{*}{$0.027 *$} \\
\hline No & $13(48.1 \%)$ & $65(73.0 \%)$ & $1(33.3 \%)$ & & \\
\hline
\end{tabular}

Psychiatric illness in the family and past history of psychiatric illness had statistically significant contribution to stress in pregnancy.

Addictions - smoking and indulge in alcohol in spouse and domestic abuse did not correlate with postnatal stress.
Support from spouse and in-laws was a negative predictor of developing both postnatal stress and depression.

Both maternal and paternal age were comparable in both groups while maternal height and weight were slightly lower in PSS (0-13) than cases and hence not statistically significant. Planned pregnancy being a significant predictor of stress as evidenced by babies of stressed 
mothers weighing nearly 100 grams lower than the controls. Babies of mothers with PSS >14 spent significantly more days in NICU. Mean GA at delivery in weeks was 36.976 .

Table 6: Psychological issues-does it affect postnatal stress ?

\begin{tabular}{|llllll|}
\hline Personal history of depression & PSS-Mild & PSS-MOD & PSS-Severe & Chi square & p-value \\
\hline Yes & $1(3.7 \%)$ & $14(15.7 \%)$ & $3(100 \%)$ & \multirow{2}{*}{19.603} & \multirow{2}{*}{$0.001^{*}$} \\
\hline No & $26(96.3 \%)$ & $75(84.3 \%)$ & $0(0.0 \%)$ & & \\
\hline Psychiatric illness in family & & & & \multirow{2}{*}{$0.001^{*}$} \\
\hline Yes & $1(3.7 \%)$ & $9(10.1 \%)$ & $3(100 \%)$ & \multirow{2}{*}{25.968} & \\
\hline No & $26(96.3 \%)$ & $80(89.9 \%)$ & $0(0.0 \%)$ & & \multirow{2}{*}{0.239} \\
\hline Self esteem & & & & \\
\hline Low & $7(25.9 \%)$ & $21(23.6 \%)$ & $2(66.7 \%)$ & 2.865 & \\
\hline Good & $20(74.1 \%)$ & $68(76.4 \%)$ & $1(33.3 \%)$ &
\end{tabular}

Table 7: Postnatal stress and spouse habits.

\begin{tabular}{|c|c|c|c|c|c|}
\hline Alcohol spouse & PSS-Mild & PSS-MOD & PSS-Severe & Chi square & p-value \\
\hline Yes & $2(7.4 \%)$ & $19(21.3 \%)$ & $0(0.0 \%)$ & \multirow[b]{2}{*}{3.430} & \multirow[b]{2}{*}{0.180} \\
\hline No & $25(92.6 \%)$ & $70(78.7 \%)$ & $3(100 \%)$ & & \\
\hline \multicolumn{6}{|l|}{ Smoking spouse } \\
\hline Yes & $4(14.8 \%)$ & $19(21.3 \%)$ & $1(33.3 \%)$ & \multirow{2}{*}{0.881} & \multirow{2}{*}{0.644} \\
\hline No & $23(85.2 \%)$ & $70(78.7 \%)$ & $2(66.7 \%)$ & & \\
\hline \multicolumn{6}{|l|}{ Physical abuse } \\
\hline Yes & $2(7.4 \%)$ & $12(13.5 \%)$ & $0(0.0 \%)$ & \multirow{2}{*}{1.147} & \multirow{2}{*}{0.564} \\
\hline No & $25(92.6 \%)$ & $77(86.5 \%)$ & $3(100 \%)$ & & \\
\hline
\end{tabular}

Table 8: Postnatal stress and support systems.

\begin{tabular}{|c|c|c|c|c|c|}
\hline Relationship with spouse & PSS-Mild & PSS-Moderate & PSS-Severe & Chi square & p-value \\
\hline Good & $21(77.8 \%)$ & $62(69.7 \%)$ & $0(0.0 \%)$ & \multirow{2}{*}{7.742} & \multirow{2}{*}{$0.021^{*}$} \\
\hline Not good & $6(22.2 \%)$ & $27(30.3 \%)$ & $3(100 \%)$ & & \\
\hline \multicolumn{6}{|c|}{ Adequate relationship with parents } \\
\hline Good & $24(88.9 \%)$ & $74(83.1 \%)$ & $3(100 \%)$ & \multirow{2}{*}{1.081} & \multirow{2}{*}{0.583} \\
\hline Not good & $3(11.1 \%)$ & $15(16.9 \%)$ & $0(0.0 \%)$ & & \\
\hline \multicolumn{6}{|l|}{ Relationship with in-law's } \\
\hline Good & $21(77.8 \%)$ & $60(67.4 \%)$ & $0(0.0 \%)$ & \multirow{2}{*}{7.583} & \multirow{2}{*}{$0.023^{*}$} \\
\hline Not good & $6(22.2 \%)$ & $29(32.6 \%)$ & $3(100 \%)$ & & \\
\hline \multicolumn{6}{|l|}{ Support in handling } \\
\hline Yes & $17(63.0 \%)$ & $47(52.8 \%)$ & $1(33.3 \%)$ & \multirow{2}{*}{1.424} & \multirow{2}{*}{0.491} \\
\hline No & $10(37.0 \%)$ & $42(47.2 \%)$ & $2(66.7 \%)$ & & \\
\hline
\end{tabular}

Table 9: Mean characteristics of the group.

\begin{tabular}{|lllll|}
\hline Variables & Mean $(\mathbf{n}=\mathbf{1 1 9})$ & PSS (perceived stress scale) & Significance* \\
\hline & & $\mathbf{0 - 1 3}$ (Mild) & $\mathbf{> 1 4}(\mathbf{M O D}$ and SEV) & \\
\hline Maternal age & 27.13 & 27.07 & 27.15 & 0.933 \\
\hline Paternal age & 33.00 & 33.78 & 32.77 & 0.329 \\
\hline Planned pregnancy & 1.15 & 1.41 & 1.08 & $0.001^{*}$ \\
\hline Age at marriage & 22.73 & 23.04 & 22.64 & 0.623 \\
\hline Maternal height & 157.02 & 156.00 & 157.32 & 0.286 \\
\hline Maternal weight & 67.03 & 67.00 & 67.03 & 0.991 \\
\hline Baby weight & 2695.64 & 2761.30 & 2676.37 & 0.604 \\
\hline GA at delivery in weeks & 36.976 & 37.567 & 36.802 & 0.303 \\
\hline NICU days & 6.84 & 3.25 & 8.00 & $0.019^{*}$ \\
\hline
\end{tabular}

*Independent sample t-test. 


\section{DISCUSSION}

Among the sociodemographic factors, we could not demonstrate any relevant association of pregnancy related stress with maternal/paternal age, mother's education and occupation; and husband's education similar to Nath et al. ${ }^{28}$ A study reported that younger women were at a higher risk for pregnancy-related anxiety. ${ }^{29}$ In regard to the relationship of stress with a woman's education, different studies report conflictive findings. While Lau and Yin opined that well educated women could handle stress in a better way during pregnancy; various studies claim that the stress levels could be much higher in this group. The burden of anxiety and stress was seemingly higher among women who belonged to lower socioeconomic classes; which is in concurrence with other study results. ${ }^{28-31}$ However, Kingston et al and Renae Stancil et al, found lower levels of stress in lower income group women. ${ }^{32}$ Authors found no significant relationship between the kind of husbands' job and perceived stress by pregnant mothers. This result is contrast with Farkas and Valdes's analysis. ${ }^{33}$

This research could not find any important linkage between stress and obstetric history, although many studies show higher levels of anxiety and stress among primiparous women. ${ }^{34,35}$

Also, an unplanned pregnancy or a history of medical complaint did not appear to predispose to prenatal anxiety in Nath et al while authors research and similar studies identified unplanned pregnancy to be significant predictor of stress in pregnancy. ${ }^{36.37}$ The prevalence of perceived stress was significantly higher among women who were depressed in the present study as in Nath et al.

Increased perceived social and partner support and adequate in-laws support appear to decrease the risk for antenatal anxiety/stress in this study as in another study. ${ }^{38,39}$ Gender fear issues were not a predictor of postnatal stress in this research in contrast to Johnson et al where desire for male child was significantly associated with mental morbidities. ${ }^{39}$ Impact of breastfeeding on both stress and immunity has been crucial in development of postnatal stress and depression..$^{40,41}$

The present study had some limitations that should be considered for further studies. The questionnaire for specific pregnancy stress was long. Therefore, some respondents got exhausted to reply them completely. Secondly, the mood of women at the time of filling the questionnaire might had influence on their response. Finally, with a quantitative research, we cannot immerse in depth of women's feeling about their stress and their financial and social needs. Future research should be focused upon widespread community-based studies to estimate prevalence of stress in a general population of pregnant women because much of the estimates in the current literature are derived from hospital-based studies.

\section{CONCLUSION}

In this research, unsatisfactory relationship with spouse and in laws along with unplanned pregnancy were the predictors of stress in pregnancy. Extended NICU stay and breastfeeding difficulties were positively associated with maternal stress. Previous history of depression and psychiatric issues accelerated the development of stress during pregnancy.

Considering the adverse neonatal outcomes and psychological ill-health of new mothers, it is important to include screening and treatment of mental morbidity as a part of routine antenatal care in India.

\section{ACKNOWLEDGMENTS}

Authors would like to thank department of Obstetrics and gynecology and department of Psychiatry, Travancore Medical College for their support during study.

Funding: No funding sources

Conflict of interest: None declared

Ethical approval: The study was approved by the Institutional Ethics Committee

\section{REFERENCES}

1. Elsenbruch S, Benson S, Rücke M, Rose M, Dudenhausen J, Pincus-Knackstedt MK, et al. Social support during pregnancy: effects on maternal depressive symptoms, smoking and pregnancy outcome. Human Reprod. 2007;22(3):869-77.

2. Talley L. Stress management in pregnancy. Int $\mathbf{J}$ Childbirth Educat. 2013;28(1):1.

3. Ruiz R, Fullerton J. The measurement of stress in pregnancy. Nurs Health Sci. 1999;1(1):19-25.

4. Littleton HL, Breitkopf CR, Berenson AB. Correlates of anxiety symptoms during pregnancy and association with perinatal outcomes: a metaanalysis. Am J Obstet Gynecol. 2007;196(5):424-32.

5. Cohen S, Kamarck T, Mermelstein R. A global measure of perceived stress. J Health Soc Behav. 1983;24:385-96.

6. Huizink AC, Anja C. Prenatal stress exposure and temperament: a review. Eur J Dev Sci. 2008;2:77-99.

7. Shiva KBK, Krishnamurthy CN. Psychological factors affecting outcome of pregnancy. Ahhs. 2015;2(1):44-9.

8. Philipp M, Brede ME, Hadmek K, Gessler M, Lohse MJ, Hein L. Placental alpha-2 adrenoreceptors control vascular development at the interface between mother and embryo. Nat Genet J. 2002;31(1):311-5.

9. Bale TL, Baram TZ, Brown AS, Goldstein JM, Insel TR, McCarthy MM. Early life programming and neurodevelopmental disorders. Biol Psych. 2010;68(4):314-9.

10. Bilbo SD, Schwarz JM. Early-life programming of later-life brain and behavior: a critical role for the 
immune system. Frontiers Behavioral Neurosci. 2009;3.

11. Divney AA, Sipsma H, Gordon D, Niccolai L, Magriples U, Kershaw T. Depression during pregnancy among young couples: The effect of personal and partner experiences of stressors and the buffering effects of social relationships. J Pediatr Adoles Gynecol. 2012;25(3):201-7.

12. Verbeek T, Bockting CL, van Pampus MG, Ormel J, Meijer JL, Hartman CA, et al. Postpartum depression predicts offspring mental health problems in adolescence independently of parental lifetime psychopathology. J Affect Disord. 2012;136(3):94854.

13. Holzman CD, Eyster J, Tiedje LB, Roman LA, Seagull E, Rahbar MH. A life course perspective on depressive symptoms in mid-pregnancy. Maternal Child Health J, 2006;10(2):127-38.

14. Lancaster CA, Gold KJ, Flynn HA, Yoo H, Marcus SM, Davis MM. Risk factors for depressive symptoms during pregnancy: a systematic review. Am J Obstet Gynecol. 2010;202(1):5-14.

15. Records K, Rice M. Psychosocial correlates of depression symptoms during the third trimester of pregnancy. J Obstet Gynecol Neonat Nurs. 207;36(3):231-42.

16. van Os J, Selten JP. Prenatal exposure to maternal stress and subsequent schizophrenia. The May 1940 invasion of The Netherlands. The $\mathrm{Br} \mathrm{J}$ Psychiatr. 1998;172(4):324-6.

17. Khashan AS, Abel KM, McNamee R, Pedersen MG, Webb RT, Baker PN, et al. Higher risk of offspring schizophrenia following antenatal maternal exposure to severe adverse life events. Arch General Psyc. 2008;65(2):146.

18. Dunkel Schetter C. Psychological science on pregnancy: stress processes, biopsychosocial models, and emerging research issues. Annual Review Psychol. 2011;62:531-58.

19. Da Costa D, Dritsa M, Verreault N, Balaa C, Kudzman J, Khalifé S. Sleep problems and depressed mood negatively impact health-related quality of life during pregnancy. Arch Women's Mental Health. 2010;13(3):249-57.

20. Lau Y, Yin L. Maternal, obstetric variables, perceived stress and health-related quality of life among pregnant women in Macao, China. Midwifery. 2011;27(5):668-73.

21. Kingston D, Heaman M, Fell D, Dzakpasu S, Chalmers B. Factors associated with perceived stress and stressful life events in pregnant women: findings from the Canadian maternity experiences survey. Maternal Child Health J. 2012;16(1):158-68.

22. Whitehead N, Brogan D, Blackmore-Prince C, Hill $\mathrm{H}$. Correlates of experiencing life events just before or during pregnancy. J Psychosomat Obstet Gynecol. 2003;24(2):77-86.

23. Lever JP. Poverty, stressful life events, and coping strategies. The Spanish J Psychol. 2008;11(1):228 49.
24. Glazier RH, Elgar FJ, Goel V, Holzapfel S. Stress, social support, and emotional distress in a community sample of pregnant women. J Psychosom Obstet Gyneacol. 2004;25(3-4):247-55.

25. Bonari L, Pinto N, Ahn E, Einarson A, Steiner M, Koren G. Perinatal risks of untreated depression during pregnancy. Can J Psychiatry. 2004;49(11):726-35.

26. Alder J, Fink N, Bitzer J, Hösli I, Holzgreve W. Depression and anxiety during pregnancy: a risk factor for obstetric, foetal and neonatal outcome? A critical review of the literature. J Matern Fetal Neonatal Med. 2007;20(3):189-209.

27. ACOG committee psychosocial risk factors perinatal screening and intervention. Obstet Gynecol. 2006;108:469-77.

28. Nath A, Murthy G, Babu G, Di Renzo G. Effect of prenatal exposure to maternal cortisol and psychological distress on infant development in Bengaluru, southern India: a prospective cohort study. BMC Psychiatry. 2017;17(1):255.

29. Madhavanprabhakaran GK, D’Souza MS, Nairy KS. Prevalence of pregnancy anxiety and associated factors. IJANS. 2015;3:1.

30. Goyal D, Gay C, Lee KA. How much does low socioeconomic status increase the risk of prenatal and postpartum depressive symptoms in first-time mothers? Women's Health Issues. 2010;20(2):96104.

31. Woods SM, Melville JL, Guo Y, Fan MY. Psychosocial stress during pregnancy. Am J Obstet Gynecol. 2010;202(1):e61-7.

32. Farkas C, Valdés N. Maternal stress and perceptions of self-efficacy in socioeconomically disadvantaged mothers: an explicative model. Infant Behav Develop. 2010;33(4):654-62.

33. Renae Stancil T, Hertz-Picciotto I, Schramm M, Watt-Morse M. Stress and pregnancy among African- American women. Paediatr Perinat Epidemiol. 2000;14(2):127-35.

34. Öhmann SG, Grunewald C, Walndenström U. Women's worries during pregnancy: testing the Cambridge Worry Scale on 200 Swedish women. ScandJ Caring Sci. 2003;17:148-52.

35. Lobel M, Cannella DL, Graham JE, DeVincent C, Schneider J, Meyer BA. Pregnancy-specific stress, prenatal health behaviors, and birth outcomes. Health Psychol. 2008;27:604-15.

36. Alqahtani AH, Al Khedair K, Al-Jeheiman R, AlTurki HA, Al Qahtani NH. Anxiety and depression during pregnancy in women attending clinics in a university hospital in eastern province of Saudi Arabia: prevalence and associated factors. Int $\mathbf{J}$ Womens Health. 2018;10:101-8.

37. van Heyningen T, Honikman S, Myer L, Onah MN, Field S, Tomlinson M. Prevalence and predictors of anxiety disorders amongst low-income pregnant women in urban South Africa: a cross-sectional study. Arch Womens Ment Health. 2017;20(6):76575 . 
38. Cheng ER, Rifas-Shiman SL, Perkins M. The influence of antenatal partner support on pregnancy outcomes. J Womens Health (Larchmt). 2016;25:672-9.

39. Johnson AR, George M, Goud BR, Sulekha T. Screening for mental health disorders among pregnant women availing antenatal care at a government maternity hospital in Bengaluru City. Indian J Psychol Med. 2018;40:343-8.

40. Kendall-Tackett K. A new paradigm for depression in new mothers: the central role of inflammation and how breastfeeding and anti-inflammatory treatments protect maternal mental health. Int Breastfeed J. 2007;2:6.
41. Dozier AM, Nelson A, Brownell E. The relationship between life stress and breastfeeding outcomes among low-income mothers. Adv Prev Med. 2012;2012:902487.

Cite this article as: Shenoy HT, Remash K, Shenoy ST. Screening for perceived stress among pregnant women availing antenatal care at a tertiary care teaching institution in Kerala, India. Int J Reprod Contracept Obstet Gynecol 2020;9:3279-87. 